\title{
REM Sleep Is Causal to Successful Consolidation of Dangerous and Safety Stimuli and Reduces Return of Fear after Extinction
}

\author{
@Mareike M. Menz, Julia S. Rihm, and Christian Büchel \\ NeuroimageNord, Department for Systems Neuroscience, University Medical Center Hamburg-Eppendorf, 20246 Hamburg, Germany
}

\begin{abstract}
Sleep has a profound impact on memory consolidation. In this study, human participants underwent Pavlovian conditioning and extinction before we manipulated nocturnal memory consolidation by a split-night protocol with 80 healthy male participants in four groups. Recall after a second (recovery) night of sleep revealed that sleeping the first half of the night, which is dominated by slow-wave sleep, did not improve recall. Conversely, sleeping the second half of the night, which is dominated by rapid eye movement (REM) sleep, led to better discrimination between fear-relevant and neutral stimuli in behavioral and autonomic measures. Meanwhile, staying awake in the second half of the night led to an increase of discrimination between extinguished and neutral stimuli, which was paralleled by an activation of the ventromedial prefrontal cortex and amygdala. We conclude that sleep, especially REM sleep, is causal to successful consolidation of dangerous and safety stimuli and reduces return of fear after extinction.
\end{abstract}

Key words: anxiety; fMRI; learning; memory; REM; sleep

\section{Significance Statement}

We use a split-night protocol to investigate the influence of different sleep phases on successful consolidation of conditioned fear and extinction. Such a protocol uses the fact that in humans the first half of the night is dominated by slow-wave sleep, whereas during the second half, rapid eye movement (REM) sleep is more predominant. Our data show that only REM-rich sleep during the second half of the night promoted good discrimination between fear-relevant and neutral stimuli during recall, while staying awake led to a recovery of discrimination between extinguished and neutral stimuli. This suggests that sleep following extinction contributes independently to successful extinction memory consolidation.

\section{Introduction}

It is well established that sleep can promote memory consolidation (Maquet, 2001; Walker and Stickgold, 2006; Diekelmann and Born, 2010). There is growing evidence that rapid eye movement (REM) sleep plays a specific role in emotional memory consolidation (Goldstein and Walker, 2014), especially in fear memory consolidation (for recent reviews, see Genzel et al., 2015; Pace-Schott et al., 2015), although few studies focus on night sleep and even fewer on specific sleep stages within the night.

Received Aug. 17, 2015; revised Dec. 21, 2015; accepted Dec. 24, 2015.

Author contributions: M.M.M. and C.B. designed research; M.M.M. and J.S.R. performed research; M.M.M. and J.S.R. analyzed data; M.M.M., J.S.R., and C.B. wrote the paper.

This work was supported by the Deutsche Forschungsgemeinschaft (SFB 654 Project A12, to C.B. and M.M.M.; and SFB-TR 58 Project B03, to C.B.). The authors thank Katrin Müller, Kathrin Wendt, and Timo Krämer for their support with MR scanning, and Jürgen Finsterbusch for setting up the fMRI protocol. We thank Judith Peth for her efforts, Tina Lonsdorf and Jan Haaker for assistance with the manuscript, and the Zonta Club Hamburg-Alster for support.

The authors declare no competing financial interests.

Correspondence should be addressed to Dr. Mareike Menz, University Medical Center Hamburg-Eppendorf, Department for Systems Neuroscience, Martinistraße 52, 20246 Hamburg, Germany. E-mail: m.menz@uke.de.

DOI:10.1523/JNEUROSCI.3083-15.2016

Copyright $\odot 2016$ the authors $\quad 0270-6474 / 16 / 362148-13 \$ 15.00 / 0$
Effects of slow-wave sleep (SWS) manipulations on consolidation are mainly reported for other domains, such as episodic and procedural memories (Maquet, 2001; Diekelmann and Born, 2010), and only occasionally for emotional memory (Hauner et al., 2013; Ai et al., 2015).

Previously, we observed that recall of learned fear was facilitated by sleep, as indicated by stronger explicitly perceived anxiety and autonomic nervous responses. These effects were positively correlated with the time individual subjects spent in REM sleep and paralleled by activation of the basolateral amygdala (Menz et al., 2013).

The present study further aims to (1) test for the causal role of REM sleep on fear and extinction memory and (2) disentangle the differential roles of SWS and REM sleep for fear learning and extinction by using a split-night design. Such a paradigm uses the fact that in humans the first half of the night is usually dominated by SWS with only short or no REM-sleep phases, whereas during the second half, REM-sleep phases are more pronounced and SWS tends to fade (Yaroush et al., 1971; Fowler et al., 1973; Plihal and Born, 1997, 1999; Gais et al., 2000).

To investigate the effects of sleep on fear learning, we used classical fear conditioning and immediate extinction as an estab- 
Table 1. Group statistics for age, questionnaires, and sleep data (means and SD)

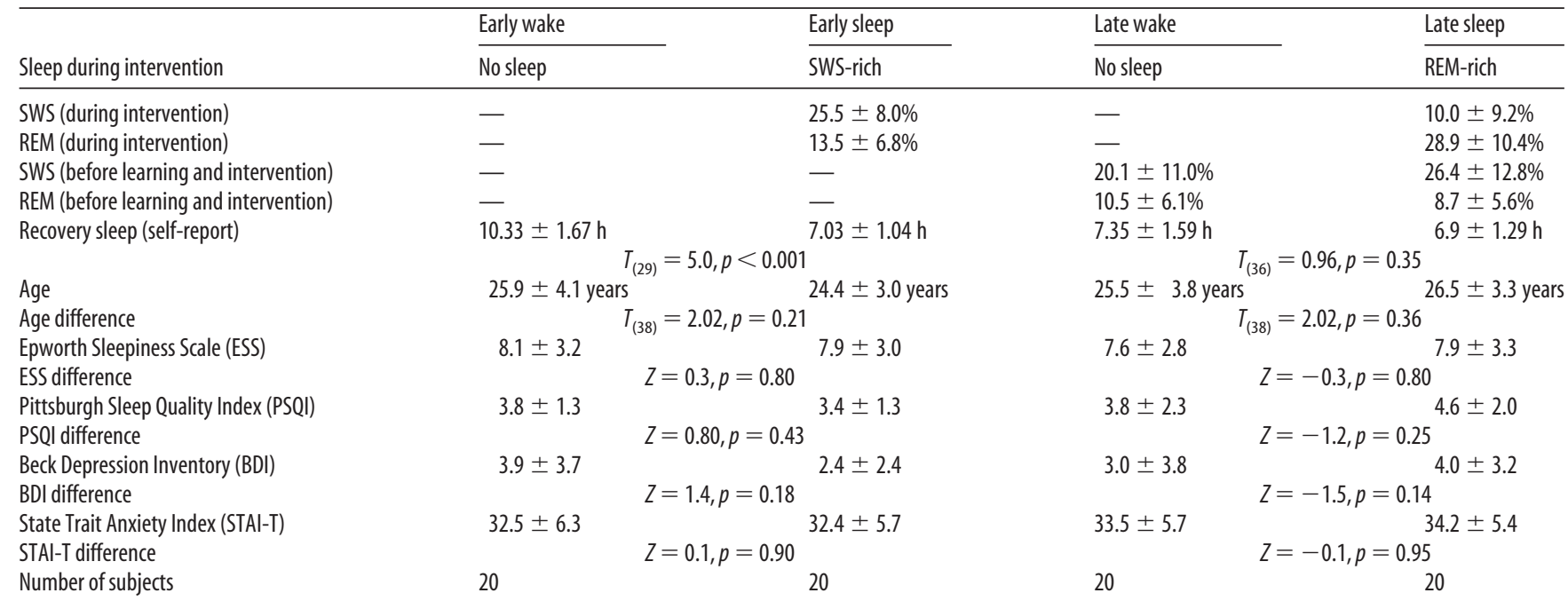

lished laboratory model for acquisition and treatment of anxiety (Vervliet et al., 2013). Four different stimuli were used to disentangle fear memory from extinction memory by comparing two of them independently to safe stimuli. This design aims to target the proposed two coexisting memory traces for conditioning and extinction learning (Pavlov, 1927; Bouton, 2004; Rescorla, 2004; Myers and Davis, 2007) to examine whether sleep and sleep stages influence the consolidation of fear or extinction memory. Sleep intervention took place the night immediately following fear and extinction learning. To investigate the influence of SWS, we first compared fear memory recall in subjects who slept the first half of the night, after learning (early sleep group) with subjects who did not have an opportunity to sleep (early wake group). In addition and to target the influence of REM sleep, we then compared subjects who continued sleeping after learning (late sleep group) with subjects who spent the second half of the night awake (late wake group). A random assignment of participants to sleep intervention groups precluded a systematic effect of the individual learning abilities and experiences on sleep architecture (Ambrosini et al., 1992; Maquet, 2001; Sanford et al., 2003; Smith et al., 2004; Suchecki et al., 2012) that may itself result in changes of consolidation and recall.

Recall performance was tested after a second (recovery) night of sleep using explicit memory testing (shock expectancy ratings), autonomic responses (skin conductance), and brain activation [functional magnetic resonance imaging (fMRI)]. Successful fear memory consolidation was operationalized as maintained discrimination of danger and safety signals in behavioral, autonomic, and neuronal responses, especially in the amygdala (Menz et al., 2013). Meanwhile, extinction memory consolidation was operationalized as maintenance of no discrimination, or comparably weaker discrimination, between extinguished and safety signals. Here the neuronal region of interest was the ventromedial prefrontal cortex (vmPFC; Milad and Quirk, 2002; Milad et al., 2007; Spoormaker et al., 2012).

We hypothesized that recall performance would improve when sleeping after fear and extinction learning compared with staying awake. More importantly, we hypothesized that memory consolidation would profit especially from sleeping during the second, REM-dominated half of the night.

\section{Materials and Methods}

Eighty healthy right-handed male volunteers underwent successful data acquisition $[25.6 \pm 3.6$ years of age $($ mean $\pm \mathrm{SD})]$. All participants had normal or corrected-to-normal vision and none had a self-reported history of psychiatric or neurological disorders (formal questionnaire). Participants reported normal daytime sleepiness $(7.9 \pm 3.1)$ as assessed using the Epworth Sleepiness Scale (Johns, 1991), normal sleep quality $(3.9 \pm 1.8)$ as assessed using the Pittsburgh Sleep Quality Index (Buysse et al., 1989), and normal sleep-wake cycles during the 4 weeks before the experiment. This was verbally assessed during initial contact (candidate participants were excluded if they worked night shifts, experienced current or past sleep disorders or problems, took sleep medications in the past or present, felt intense stress and/or learning challenges (such as examinations) in the last 4 weeks). Participants did not show any depressive symptoms as assessed by the Beck Depression Inventory (3.2 \pm 3.2 ) and revealed normal trait anxiety as measured by the State Trait Anxiety Inventory (33.1 \pm 5.8$)$. Table 1 shows details of all groups. The study was approved by the local ethics committee.

Two or three days before the experiment, all participants were invited to a question-and-answer meeting where they were informed about the procedures, filled in the medical questionnaire, confirmed normal sleep patterns, were screened by a physician, and gave written informed consent to participate in the study. Before leaving, every participant was instructed to be prepared for either sleep intervention, i.e., bring comfortable clothes and hygiene articles as well as light activities to occupy themselves (physical activities or intense mental and novel activities that would induce learning were not allowed). Finally, they were reminded to sleep as usual until the beginning of the experiment.

Sleep intervention and groups. Participants were randomly assigned to one of four sleep-intervention groups (Fig. 1): 40 participants underwent conditioning and immediate extinction in the evening and either spent only the first half of the night after learning asleep (early sleep group, $n=$ 20 ) or stayed awake until morning (early wake group, $n=20$ ). Another forty participants were allowed to sleep the first half of the night before they performed the fear and extinction learning paradigm. After learning, they either spent the second half of the night asleep (late sleep group, $n=20$ ) or stayed awake (late wake group, $n=20$ ). Data from the early wake group were previously reported in comparison with data from a group with a full night of sleep (Menz et al., 2013). Participants were blind with respect to group assignment until the beginning of sleep intervention.

All experimental sessions started between 8:00 and 9:00 P.M. Half of the subjects (early wake and early sleep groups) first underwent the conditioning and extinction of fear memory while explicit shock expectancy ratings, autonomic responses (skin conductance), and brain activation (fMRI) were acquired. Subjects of the early sleep group $(n=20)$ were then prepared for standard polysomnographic recordings (including EEG, EOG, and EMG recordings) and went to sleep for $\sim 3.5 \mathrm{~h}$ to be awake during the second half of the night. Subjects of the early wake group $(n=20)$, meanwhile, spent the whole night awake. The other half 


\section{early night late night}

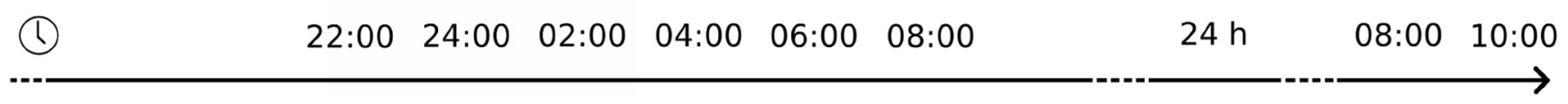
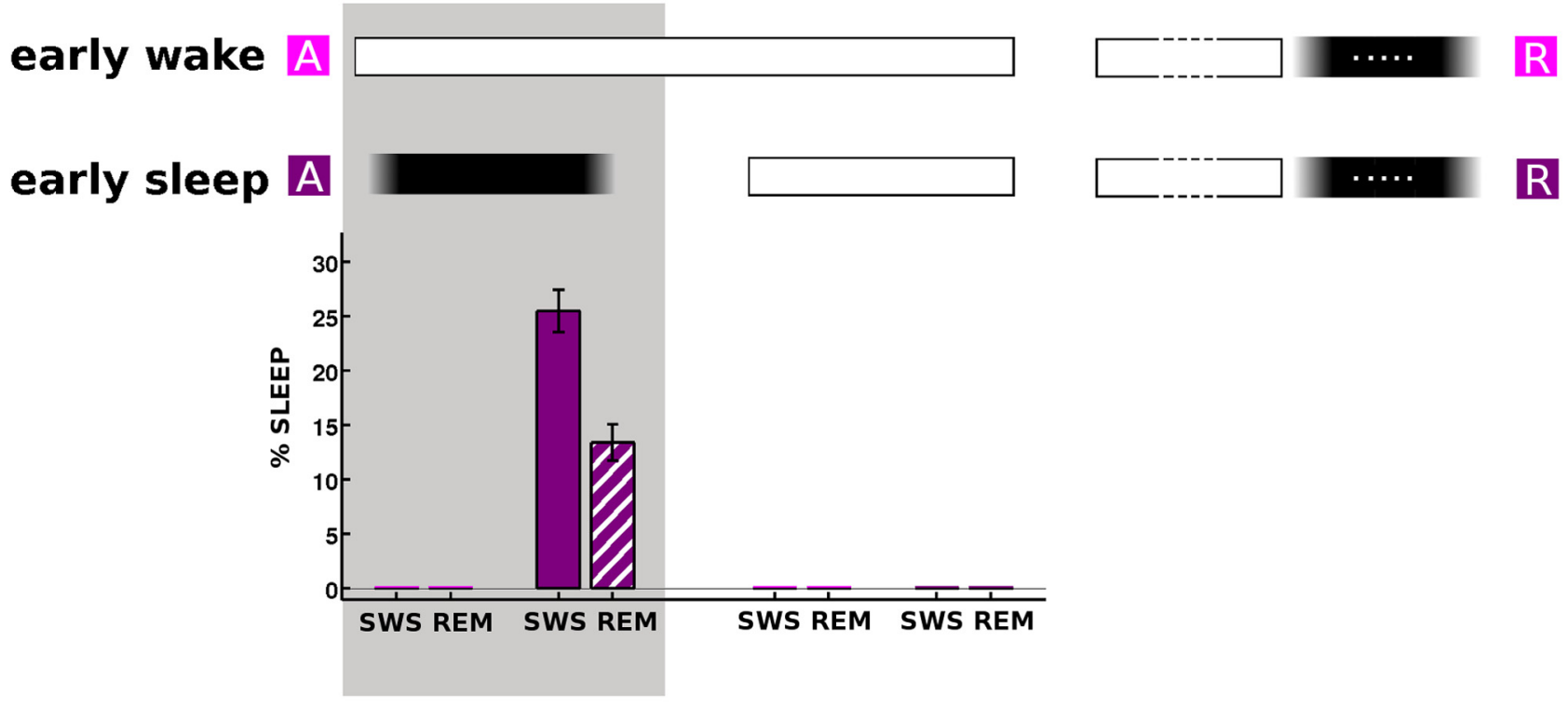

late wake
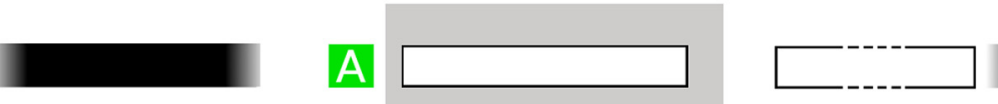

$\cdots$

$\mathbf{R}$

late sleep
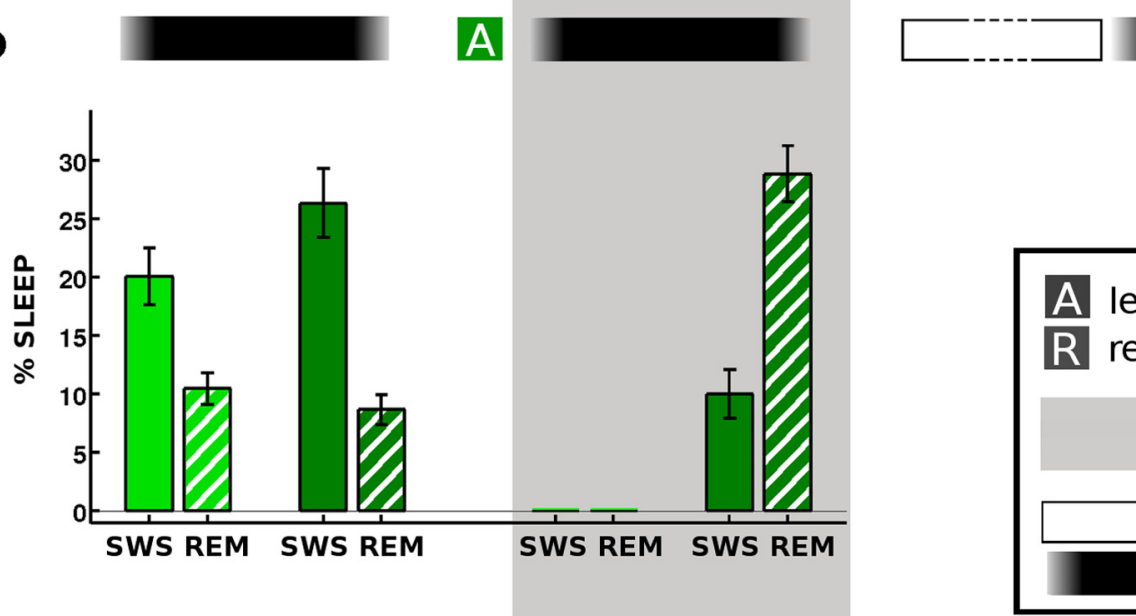

$\cdots$

$\mathbf{R}$

A learning on day 1

$R$ recall on day 3

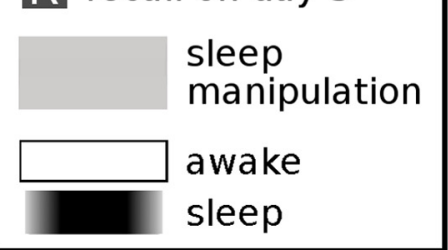

Figure 1. Experimental setup and sleep manipulation. Participants in early night sleep manipulation groups took part in a classical conditioning paradigm with immediate extinction in the evening before they were allowed to sleep for half a night (early sleep group) or had to stay awake until morning (early wake group). Participants in the late night sleep manipulation groups slept the first half of the night, before they were woken up for the conditioning and extinction paradigm. Then they were either allowed to go back to sleep (late sleep group) or required to stay awake until morning (late wake group). In the first half of the night/early night, sleep consisted of more SWS than REM sleep (early sleep and late night groups), while in the second half of the night/late night, REM sleep was more pronounced (late sleep group only; bars indicate mean and SEM).

of the subjects (late wake and late sleep groups) were immediately prepared for polysomnographic recordings before they went to bed. They were allowed to read or watch a movie before lights were turned off to enable sleep for $\sim 3.5 \mathrm{~h}$. They were woken up from light sleep as determined by on-line EEG recordings and remained in a dimly lit environment for $\geq 45$ min before they underwent fear conditioning and extinction as described for the early night groups. After the fMRI paradigm, the late sleep group was again prepared for polysomnography and continued sleeping until morning (wake up ad libitum). The late wake group spent the second half of the night awake.

While awake, participants were allowed to follow standard activities during the night (reading, watching a movie, playing card games with the experimenter), during which they were under constant visual monitoring by the experimenter until 8:00 A.M. During this time as well as during the following day, physical activities, intense mental activities, and novel activities that would induce learning were not permitted. Also, partici- 
pants were asked to refrain from alcohol and caffeine. On day 2, sleep was monitored by a scoring sheet ("sleep protocol") in which participants were asked to record bed times, sleep duration, subjective sleep quality, and alcohol intake, and by Actiwatch 2 recordings (Philips Respironics). All participants were instructed not to nap. Apart from these restrictions, participants from all four groups were free to spend their time on day 2 "as usual." There was no further supervision under laboratory conditions until they returned for the recall session on day 3 following a recovery night of sleep at home. The recall session took place between 8:00 and 10:00 A.M.

Task. We used an established $2 \mathrm{~d}$ paradigm (Menz et al., 2013) with conditioning and immediate extinction on day 1 and recall on day 3.

Throughout the experiment, four different stimuli (circle, square, triangle, or cross) were presented overlaid on a context picture (one of two different neutral pictures of a living room that were matched for emotional valence, luminance, and content/furniture). Each stimulus-context combination was presented for $6 \mathrm{~s}$, followed by an interstimulus interval of 6-11.4 s. After the first $2 \mathrm{~s}$ of stimulus presentation, expectancy ratings were assessed: participants were asked to indicate by button press (right index, middle, or ring finger) whether they would or would not expect a shock during this trial, or to give a neutral answer if unsure. During conditioning, all four stimuli were presented 10 times each on context A (one of the contexts, randomized across participants). Here, two of the stimuli were conditioned stimuli $(\mathrm{CS}+\mathrm{N}, \mathrm{CS}+\mathrm{E})$. Therefore their presentation included an unconditioned stimulus (UCS) $250 \mathrm{~ms}$ before the offset of the stimulus in 8 of 10 trials ( $80 \%$ partial reinforcement). The UCS was a mild electric stimulus consisting of a train of six 1 ms pulses at a frequency of $90 \mathrm{~Hz}$ that were delivered through a "wasp electrode" (http://www.specialty-developments.co.uk) on the back of the right hand (Digitimer Constant Current Stimulator, Digitimer). Preceding the experiment, UCS intensity was individually adapted in a staircase protocol while the participant was lying in the scanner and verbally rated the intensity of the shock. The final intensity of the shock was aversive but not painful $(4.81 \pm 4.09 \mathrm{~mA})$. The other two stimuli (CS $-\mathrm{N}$, CS-E; 10 times each) were never paired with a shock.

In the immediately following extinction procedure, only two stimuli $(\mathrm{CS}+\mathrm{E}$ and $\mathrm{CS}-\mathrm{E})$ were presented (10 times each) without further reinforcement and on context B. During recall on day 3, all four stimuli $(\mathrm{CS}+\mathrm{N}, \mathrm{CS}+\mathrm{E}, \mathrm{CS}-\mathrm{N}, \mathrm{CS}-\mathrm{E} ; 10$ times each) were presented again; $\mathrm{CS}+\mathrm{N}$ and $\mathrm{CS}-\mathrm{N}$ were presented on conditioning background $\mathrm{A}$ and $\mathrm{CS}+\mathrm{E}$ and $\mathrm{CS}-\mathrm{E}$ were presented on extinction background. Thus, by comparing $\mathrm{CS}+\mathrm{N}$ to $\mathrm{CS}-\mathrm{N}$ and $\mathrm{CS}+\mathrm{E}$ to $\mathrm{CS}-\mathrm{E}$, fear memory $(\mathrm{CS}+\mathrm{N})$, extinction memory $(\mathrm{CS}+\mathrm{E})$, and safety signals $(\mathrm{CS}-)$ can be separately identified. On day 3 , UCS intensity was readjusted before the experiment without any context or cue presentation, but instead announced by the experimenter and by a flicker of a fixation cross for each calibration step to limit reinstatement effects (Haaker et al., 2014). However, no shocks were delivered during the recall session. All trials were presented in pseudorandomized order ( $\leq 2$ of each stimulus in succession, 20 randomization lists per group, counterbalanced over groups and equal distribution of stimuli over blocks and randomization lists) in blocks of 20 stimuli (two blocks during conditioning, two blocks during recall, and one block during extinction). In the fMRI scanner, participants viewed the back-projected stimuli via a $45^{\circ}$ mirror placed atop the head coil. Task presentation and recording of behavioral responses was performed with Presentation 14.2 software (NeuroBehavioral Systems).

Skin conductance responses. Skin conductance responses (SCRs) were measured continuously throughout the experiment on both days via $\mathrm{Ag} / \mathrm{AgCl}$ electrodes (6 mm diameter) placed on the palm of the left hand. The signal was amplified using a CED 2502 amplifier and sampled at 10 $\mathrm{Hz}$ using a CED 1401 analog-to-digital converter (Cambridge Electronic Design) together with a trigger signal sent from the Presentation software to mark the onsets of trials.

fMRI. For both sessions, fMRI was performed on a 3 T MR Scanner (Trio, Siemens) with a 32-channel head coil. Forty-two axial slices $(2 \mathrm{~mm}$ thickness, $50 \%$ gap) were acquired using a T2*-sensitive gradient echoplanar imaging sequence $\left(\mathrm{TR}=2.58 \mathrm{~s}\right.$; TE $=26 \mathrm{~ms}$; Slice tilt, $30^{\circ}$; flip angle, $90^{\circ}$; in-plane resolution, $2 \times 2 \mathrm{~mm}$; FOV, $220 \mathrm{~mm}$ ). Additionally, an MPRAGE structural image was acquired (voxel size, $1 \times 1 \times 1 \mathrm{~mm}$; 240 slices) for each participant.

Polysomnography. Sleep stages were determined from standard polysomnographic recordings (Brain Vision Recorder, Brain Products) with electrodes at $\mathrm{C} 3 / \mathrm{C} 4$ according to the international 10-20 system, EMG electrodes at masseters, horizontal EOG, and a reference electrode attached to the nose. Data were sampled at $250 \mathrm{~Hz}$. After filtering $(0.3-35$ $\mathrm{Hz}$ bandpass) data were scored by two trained and experienced laboratory members according to the criteria of the American Academy of Sleep Medicine (Iber, 2007). More precisely, subsequent 30 s epochs of recordings were scored visually while awake and at sleep stages $\mathrm{N} 1, \mathrm{~N} 2, \mathrm{~N} 3$, and REM. Stage N3 is SWS and contains both sleep stages S3 and S4 of the Rechtschaffen and Kales (1968) sleep-scoring criteria.

Data reduction and statistical analysis. Statistical null hypotheses were rejected at a significance level of $\alpha=0.05$. One-tailed tests with a directed hypotheses (i.e., $\mathrm{CS}+\mathrm{N}>\mathrm{CS}-\mathrm{N}$ at the end of conditioning and the beginning of recall, and sleep group $>$ wake group for recall performance) were performed.

UCS expectancy ratings were coded as follows: 0 , no shock; 0.5 , don't know; 1 , sure shock). Averaged values thus vary between 0 and 1 . Statistical testing (Matlab R2012a) for shock expectancy applied nonparametric tests, i.e., Wilcoxon signed-rank tests for differences between conditions and Wilcoxon rank-sum tests for differences between groups.

The SCRs were scored semiautomatically as the largest increase (positive difference between local maximum and preceding local minimum) in conductance occurring between 1.0 and $5.750 \mathrm{~s}$ after each stimulus onset. Trials with a response amplitude of $<0.05 \mu \mathrm{S}$ were regarded as null responses. To normalize the left-skewed distribution of SCR amplitudes, individual SCR values were log transformed (Boucsein et al., 2012). Single missing scores were replaced by the mean over subjects within group condition and trial. Within each condition, maxima of the SCRs were individually smoothed by local linear regression using weighted linear least squares and a second-degree polynomial model (Matlab loess method with span of 5) to restore individual curves after replacement of missing values and deweight possible outliers. Ten of 160 SCR datasets had to be excluded from analysis due to electrode failure $(n=7)$, breathing artifacts $(n=2)$, and conductance readings reaching saturation $(n=1)$.

Paired $t$ tests (Matlab R2012a) were applied to investigate differences between conditions and two-sample $t$ tests were applied for comparing difference scores between groups. Correlation analyses of SCRs were based on Pearson's correlations coefficients and Bonferroni-corrected for the number of ROIs $(n=2)$.

Image processing and statistical analyses were performed using SPM12 (Wellcome Trust Center for Neuroimaging, London). In a first step, single-subject echo-planar images were coregistered with the T1 structural image. After slice-timing correction to the onset of the middle slice, functional images were realigned and resliced to the first volume. A firstlevel model was constructed on the unsmoothed single-subject data of both days by using the following regressors: $\mathrm{CS}+\mathrm{E}, \mathrm{CS}+\mathrm{N}, \mathrm{CS}-\mathrm{E}$, and CS - N. As in our previous study (Menz et al., 2013), we modeled all trials separately. Button presses, UCS onsets, and motion parameters were included as regressors of no interest. Thus, there were a total of $4 \times 10 \times$ 2 (conditions $\times$ number of trials $\times$ days) regressors plus $8 \times 2$ regressors of no interest. Since skin conductance and expectancy ratings partly revealed group $\times$ condition interactions on day 1 (results section), all analyses were set up as group $\times$ condition $\times$ time interactions. Hence, $\mathrm{CS}+$ versus $\mathrm{CS}-$ effects during recall were set up as $\mathrm{CS}+_{\mathrm{DAY} 3}-$ $\mathrm{CS}-{ }_{\text {DAY3 }}$ versus $\mathrm{CS}+_{\mathrm{DAY} 1}-\mathrm{CS}-{ }_{\mathrm{DAY} 1}$ for each set of three trials. More precisely, the size of difference between CS $+\mathrm{E}$ and CS - E during the first three trials of recall was corrected by the size of difference between $\mathrm{CS}+\mathrm{E}$ and CS-E during the last three trials of extinction, while the size of difference between $\mathrm{CS}+\mathrm{N}$ and $\mathrm{CS}-\mathrm{N}$ during the first three trials of recall was corrected by the size of difference between $\mathrm{CS}+\mathrm{N}$ and $\mathrm{CS}-\mathrm{N}$ during the last three trials of conditioning. Please note that the full model included all scans. However, modeling individual events separately was necessary because testing only the first CS events (in which volunteers do not know that no UCS will be presented) can be considered a better test as late trials are subject to (second) extinction learning. 

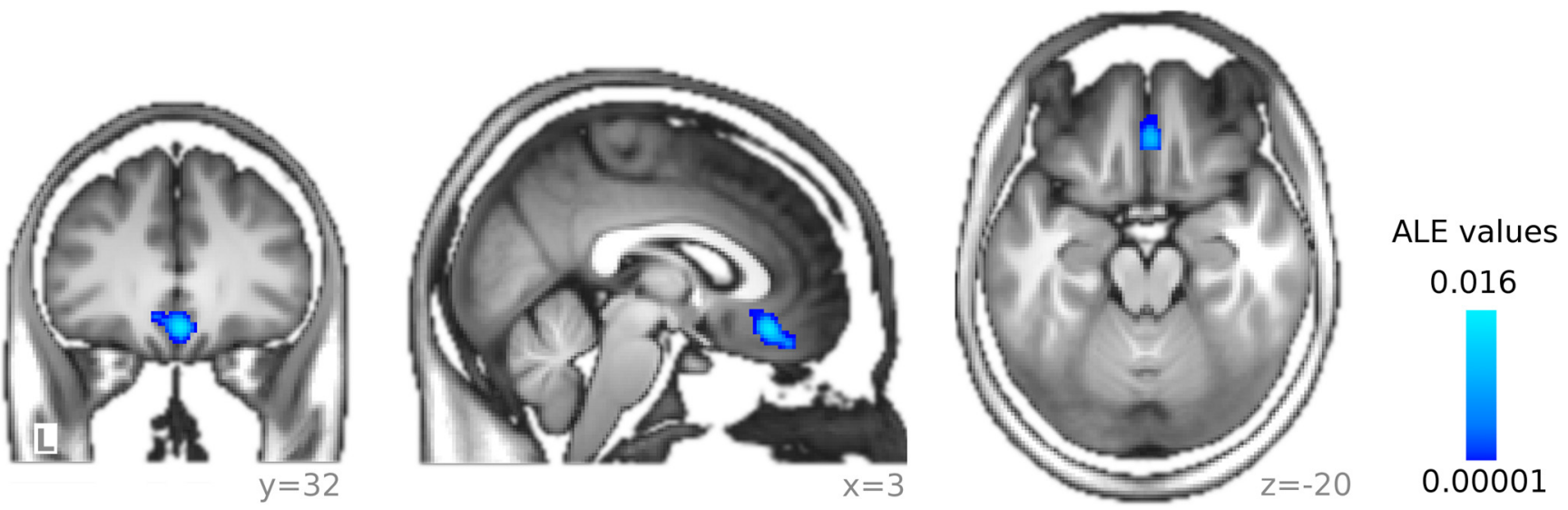

Figure 2. ALE meta-analysis on extinction recall. The vmPFC cluster ( 125 voxels, $1000 \mathrm{~mm}^{3}$ ) from an ALE meta-analysis ( 15 studies, 300 subjects) was superimposed on the mean $\mathrm{T}_{1}$ image of all participants after cluster-level inference ( $p<0.05 ; p<0.001$ cluster-forming value). Sections correspond to the peak voxel of extinction recall in this study. Blue colors indicate ALE values.

For the temporally dynamic changes during recall, an alternative second first-level model was constructed on the single-subject data of both days by using the following 10 regressors: $\mathrm{CS}+\mathrm{E}, \mathrm{CS}+\mathrm{N}, \mathrm{CS}-\mathrm{E}$, and $\mathrm{CS}-\mathrm{N}$ during conditioning; $\mathrm{CS}+\mathrm{E}$ and $\mathrm{CS}-\mathrm{E}$ during extinction; and, again, $\mathrm{CS}+\mathrm{E}, \mathrm{CS}+\mathrm{N}, \mathrm{CS}-\mathrm{E}$, and $\mathrm{CS}-\mathrm{N}$ during recall. In addition, we defined 10 explanatory variables that represent interactions of these 10 main effect regressors with time. These were created by multiplying each regressor with a linear increasing function (Marschner et al., 2008; Menz et al., 2013). Button presses in both sessions and six realignment parameters (motion) were included as regressors of no interest. All but the motion regressors were convolved with the hemodynamic response function. Next, contrast images of the parameter estimates were created for each subject and session for each condition separately, and for CS+ versus CS - effects on average, as well as in interaction with time, i.e., absolute or differential linear slope changes, respectively.

Single-subject contrast images were normalized to a DARTEL (Diffeomorphic Anatomical Registration through Exponentiated Lie Algebra) template in MNI space as provided by the VBM8 toolbox on the basis of the individual participants' DARTEL flow fields and smoothed with a 6 $\mathrm{mm}$ full-width at half-maximum Gaussian isotropic kernel. The normalized and smoothed single-subject contrast images were then taken to a second-level random-effects analysis (two-sample $t$ test of early sleep vs early wake and late sleep vs late wake, respectively).

Statistical parametric images were thresholded at $p<0.001$, uncorrected, with a cluster size of $\geq 40$ voxels. Corrections for multiple comparisons using the familywise error (FWE) rate were conducted in the amygdala and the vmPFC. The region of interest for the amygdala was derived from the Harvard-Oxford probability maps (Harvard Center for Morphometric Analysis; threshold: 0.33). For a valid region of interest of the vmPFC, we computed an activation likelihood estimation (ALE) probability map (Turkeltaub et al., 2002; Eickhoff et al., 2009, 2012; $p<$ 0.05 , cluster-level inference with cluster-forming threshold, $p<0.001$ ) on coordinates derived from 13 reports/15 extinction recall studies (Phelps et al., 2004; Kalisch et al., 2006; Milad et al., 2007, 2009; Spoormaker et al., 2010, 2012; Rougemont-Bücking et al., 2011; Menz et al., 2013; Pejic et al., 2013; Feng et al., 2014; Garfinkel et al., 2014; Hermann et al., 2014; Lonsdorf et al., 2014) and 300 healthy human subjects (only or compared with patients) that reported whole-brain activation at an uncorrected threshold of $p<0.001$. After cluster-level inference $(p<$ $0.05 ; p<0.001$ cluster-forming value) ALE results showed a large vmPFC cluster ( 125 voxels, $\left.1000 \mathrm{~mm}^{3}\right)$ centered at $x, y, z=0,36,-15\left(\right.$ ALE $_{\mathrm{MAX}}$ $=0.0169)$. This volume of interest is shown in Figure 2 .

\section{Results}

After confirming successful fear learning, we compared fear memory recall in subjects who slept the first half of the night after learning (early sleep) with subjects who did not have an opportunity to sleep (early wake). Additionally, we compared subjects who continued sleeping after learning (late sleep) with subjects who spent the second half of the night awake (late wake).

To account for individual differences preceding consolidation, we corrected all recall results by learning outcome, thereby addressing the question "How much of the learned content is maintained or forgotten?" during the different sleep phases. This recovery index (Schiller et al., 2013) is expressed as the difference between recall testing (first three trials on day 3) and learning outcome (last three trials on day 1 ). Such a differential score is widely used (and mandatory) in memory research, e.g., performance recovery (Fenn et al., 2003), gain in performance (Marshall et al., 2006), off-line memory gain in motor learning (Abe et al., 2011), or absolute location in spatial memory tasks (Smith and Milner, 1981). Importantly, this differential score provides the advantage of an unbiased view on the effect of manipulation on recall, especially with participants in different preconditions (Smith and Milner, 1981; Jokeit et al., 1997, 2001; Seidman et al., 1998; Leeson et al., 2009).

All measures (i.e., expectancy ratings, SCR amplitudes, and neural activations during recall) were corrected within condition $\left(\mathrm{CS}+\mathrm{N}_{\text {RECALL }}-\mathrm{CS}+\mathrm{N}_{\mathrm{COND}}, \mathrm{CS}-\mathrm{N}_{\mathrm{RECALL}}-\mathrm{CS}-\mathrm{N}_{\mathrm{COND}}\right.$, $\mathrm{CS}+\mathrm{E}_{\mathrm{RECALL}}-\mathrm{CS}+\mathrm{E}_{\mathrm{EXT}}$, and CS$\left.-{ }_{\text {RECALL }}-\mathrm{CS}-{ }_{\text {EXT }}\right)$ and subject. Thus all results describe changes from learning to recall within condition (see Figs. 4-6; Table 2, bottom two rows). Positive values describe a gain of fear during memory consolidation while negative values describe a decrease or loss of fear overnight. Consequently, smaller absolute differences between CS + and $\mathrm{CS}-$ during recall describe better maintenance of stimulus discrimination. This means that if bars or values do not change, recall performance on day 3 is an exact reproduction of learning outcome on day 1.

\section{Successful learning}

Subjects in all groups learned to discriminate CS + and CS - during conditioning (Fig. 3A; Table 2). During extinction, the difference between $\mathrm{CS}+\mathrm{E}$ and $\mathrm{CS}-\mathrm{E}$ ceased to exist (Fig. 3B; Table 2).

Although all groups reached successful extinction (i.e., no difference between $\mathrm{CS}+\mathrm{E}$ and $\mathrm{CS}-\mathrm{E}$ at the last three trials of extinction) differential shock expectancy ratings $(\mathrm{CS}+\mathrm{E}>\mathrm{CS}-\mathrm{E})$ tended to be larger in participants who were later randomly assigned to the late sleep group ( $p=0.09$ ). Additionally, SCRs generally tended to be larger in the late wake group compared with the late sleep group $(p=0.10)$. These findings additionally motivated the computation of recovery indices as described above. 
Table 2. Behavioral and physiological results in all experimental sessions

\begin{tabular}{|c|c|c|c|c|c|c|c|c|}
\hline & \multicolumn{2}{|l|}{ Early wake } & \multicolumn{2}{|l|}{ Early sleep } & \multicolumn{2}{|l|}{ Late wake } & \multicolumn{2}{|l|}{ Late sleep } \\
\hline & $\mathrm{CS}+$ & CS- & $\mathrm{CS}+$ & CS- & CS+ & CS- & CS+ & CS- \\
\hline \multicolumn{9}{|l|}{ Conditioning } \\
\hline \multirow[t]{2}{*}{$S C R$} & $0.46(0.09)$ & $0.24(0.05)$ & $0.33(0.08)$ & $0.15(0.05)$ & $0.18(0.05)$ & $0.10(0.05)$ & $0.11(0.03)$ & $0.06(0.03)$ \\
\hline & \multicolumn{2}{|c|}{$T_{(19)}=2.63, p=0.008$} & \multicolumn{2}{|c|}{$T_{(17)}=3.32, p=0.0002$} & \multicolumn{2}{|c|}{$T_{(14)}=1.72, p=0.054$} & \multicolumn{2}{|c|}{$T_{(16)}=2.61, p=0.009$} \\
\hline SCR-UCS & $0.99(0.01)$ & - & $1.12(0.02)$ & - & $0.76(0.03)$ & - & $0.55(0.02)$ & - \\
\hline Shock expectancy & \multicolumn{2}{|c|}{$Z=-0.732, p=0.46$} & \multicolumn{2}{|c|}{$Z=-1.75, p=0.08$} & \multicolumn{2}{|l|}{$Z=0, p=1$} & \multicolumn{2}{|c|}{$Z=-0.55, p=0.58$} \\
\hline \multirow[t]{2}{*}{$S C R$} & $0.22(0.06)$ & $0.16(0.04)$ & $0.11(0.05)$ & $0.14(0.06)$ & $0.06(0.02)$ & $0.11(0.05)$ & $0.02(0.01)$ & $0.04(0.03)$ \\
\hline & \multicolumn{2}{|c|}{$T_{(19)}=0.85, p=0.41$} & \multicolumn{2}{|c|}{$T_{(17)}=-0.45, p=0.66$} & \multicolumn{2}{|c|}{$T_{(14)}=-1.28, p=0.22$} & \multicolumn{2}{|c|}{$T_{(16)}=-0.33, p=0.74$} \\
\hline $\begin{array}{l}\text { Fear recall } \\
\text { Shock expectancy }\end{array}$ & $-0.35(0.10)$ & $0.06(0.04)$ & $-0.42(0.10)$ & $0.02(0.07)$ & $-0.55(0.10)$ & $0.06(0.05)$ & $-0.28(0.11)$ & $0.13(0.06)$ \\
\hline SCR & $\begin{array}{c}Z=-3.29, p \\
-0.22(0.07) \\
T_{10}=-1.8\end{array}$ & $\begin{array}{l}.001 \\
-0.02(0.08) \\
=0.04\end{array}$ & $\begin{array}{l}Z=-2.52, p \\
-0.23(0.07) \\
T=-2.76\end{array}$ & $\begin{array}{l}.006 \\
0.04(0.07) \\
0.007\end{array}$ & $\begin{array}{l}Z=3.14, p= \\
-0.11(0.04) \\
=-2.05\end{array}$ & $\begin{array}{l}01 \\
=0.08(0.07) \\
=0.03\end{array}$ & $\begin{array}{l}Z=-3.07, p \\
-0.002(0.04) \\
T=-0.01\end{array}$ & $\begin{array}{l}001 \\
-0.003(0.04) \\
0.50\end{array}$ \\
\hline$S C R$ & $\begin{array}{l}-0.08(0.05) \\
T_{(19)}=-0.65\end{array}$ & $\begin{aligned} & -0.03(0.05) \\
= & 0.50\end{aligned}$ & $\begin{array}{l}-0.06(0.06) \\
T_{(17)}=0.29, p\end{array}$ & $\begin{array}{l}-0.08(0.06) \\
.79\end{array}$ & $\begin{array}{c}0.03(0.03) \\
T_{(14)}=1.65, p\end{array}$ & $\begin{array}{l}-0.06(0.05) \\
0.12\end{array}$ & $\begin{array}{c}0.02(0.02) \\
T_{(16)}=-0.65,\end{array}$ & $0.53^{0.05(0.03)}$ \\
\hline
\end{tabular}

Mean and SEM are given for the last three trials of each condition in the conditioning and extinction phase (prior to sleep intervention). Mean and SEM in the recall phase (after sleep intervention) describe the shift at recall (averaged over the first 3 trials) relative to the last three stimuli of acquisition (i.e. recovery indices). Thus, positive values in fear recall and extinction recall indicate an increase in shock expectancy and skin conductance during consolidation. Statistical testing describes comparisons between $\mathrm{CS}+$ and $\mathrm{CS}$ - .

\section{Sleep}

Figure 1 displays percentage of SWS and REM sleep in all groups (Table 1). In the first half of the night, participants on average spent $23.9 \pm 11.1 \%$ of time in SWS and $10.8 \pm 6.4 \%$ of time in REM sleep. In the second half of the night (only the late sleep group was allowed to sleep), participants spent $10.0 \pm$ $9.2 \%$ of time in SWS and $28.9 \pm 10.4 \%$ of time in REM sleep, which was significantly less SWS than in the first half of the night $\left(T_{(18)}=4.65, p<0.001\right)$ and significantly more REM sleep than in the first half of the night $\left(T_{(18)}=-7.70, p<\right.$ $0.001)$.

\section{Fear recall after early and late night consolidation}

All recall results (figures and tables) are recovery indices. Thus bars in Figure 4 describe changes from learning to recall, with rising bars describing an increase in fear during memory consolidation while falling bars depict a decrease of fear overnight. Thus, perfect fear memory maintenance would result in values of zero and zero difference between $\mathrm{CS}+\mathrm{N}$ and $\mathrm{CS}-\mathrm{N}$ (Table 2, Row 3), while impaired maintenance would be expressed by larger absolute values and a large (negative) difference between $\mathrm{CS}+\mathrm{N}$ and $\mathrm{CS}-\mathrm{N}$.

Early sleep and early wake group did not differ on behavioral and neurophysiological measures during recall (Fig. 4, left). Particularly, differentiation between dangerous and safe stimuli $(\mathrm{CS}+\mathrm{N}>\mathrm{CS}-\mathrm{N})$ decreased similarly in the early wake and early sleep group. Shock expectancy ratings for fear stimuli decreased in both groups while neutral stimuli remained similar (Fig. 4, upper left; group difference for $\mathrm{CS}+\mathrm{N}>\mathrm{CS}-\mathrm{N}: Z=0.30, p=0.77)$. The same pattern can be observed for differential SCRs after consolidation during early sleep (Fig. 4, bottom left; group difference for $\mathrm{CS}+\mathrm{N}>$ $\left.\mathrm{CS}-\mathrm{N}: T_{(36)}=0.39, p=0.65\right)$. Hence, differentiation performance decreases independently from sleep intervention during early night hours. We therefore forgo further analysis of neuronal correlates on the influence of early night sleep on fear memory consolidation.
In contrast, late night sleep manipulation revealed an effect of REM-rich sleep on consolidation of fear (Fig. 4, right). More precisely, the group with the highest percentage of REM sleep during the first night of consolidation (late sleep) shows the best maintenance of differentiation between $\mathrm{CS}+\mathrm{N}$ and $\mathrm{CS}-\mathrm{N}$. More simply put, the smaller negative bar for expectancy ratings at $\mathrm{CS}+\mathrm{N}$ presentations in the late sleep group indicates less forgetting of fear compared with the larger falling bar of the late wake group. Similarly, the smaller difference between $\mathrm{CS}+\mathrm{N}$ and $\mathrm{CS}-\mathrm{N}$ in the late sleep group indicates a better maintenance of differentiation from day 1 to day 3 (Fig. 4, top right; Table 2, Row 3).

Hence, the decrease in differentiation between dangerous and safety stimuli $(\mathrm{CS}+\mathrm{N}>\mathrm{CS}-\mathrm{N})$ was larger in the late wake group compared with the late sleep group (expectancy ratings: $Z=1.93$, $p=0.03$ ). This pattern is even more pronounced in autonomic measures. Here, the SCR difference between $\mathrm{CS}+\mathrm{N}$ and $\mathrm{CS}-\mathrm{N}$ presentations decreases only in participants in the late wake group, while SCR activity stays constant in the late sleep group. Or again more simply put, SCR to $\mathrm{CS}+\mathrm{N}$ decreases and SCR to $\mathrm{CS}-\mathrm{N}$ increases, which leads to worse discrimination in the late wake group compared with the late sleep group in which SCR to both stimuli are maintained (Fig. 4, bottom right; difference between groups, $T_{(30)}=1.91, p=0.03$ ). In contrast to behavioral and autonomic measures of fear recall, neuronal measures (i.e., differential activation maps of $\mathrm{CS}+\mathrm{N}>\mathrm{CS}-\mathrm{N}$ ) did not differ between late wake and late sleep groups. Here no clusters survived statistical thresholding.

\section{Extinction recall after early and late night consolidation}

Again, all recall results (figures and tables) are recovery indices. Bars in Figure 5 describe changes from learning to recall, with rising bars describing an increase in fear during memory consolidation while falling bars depict a decrease of fear overnight. Perfect extinction memory maintenance would result in values of zero and zero difference between CS +E and CS-E (Fig. 5; Table 2 , bottom row), while impaired maintenance would be expressed 

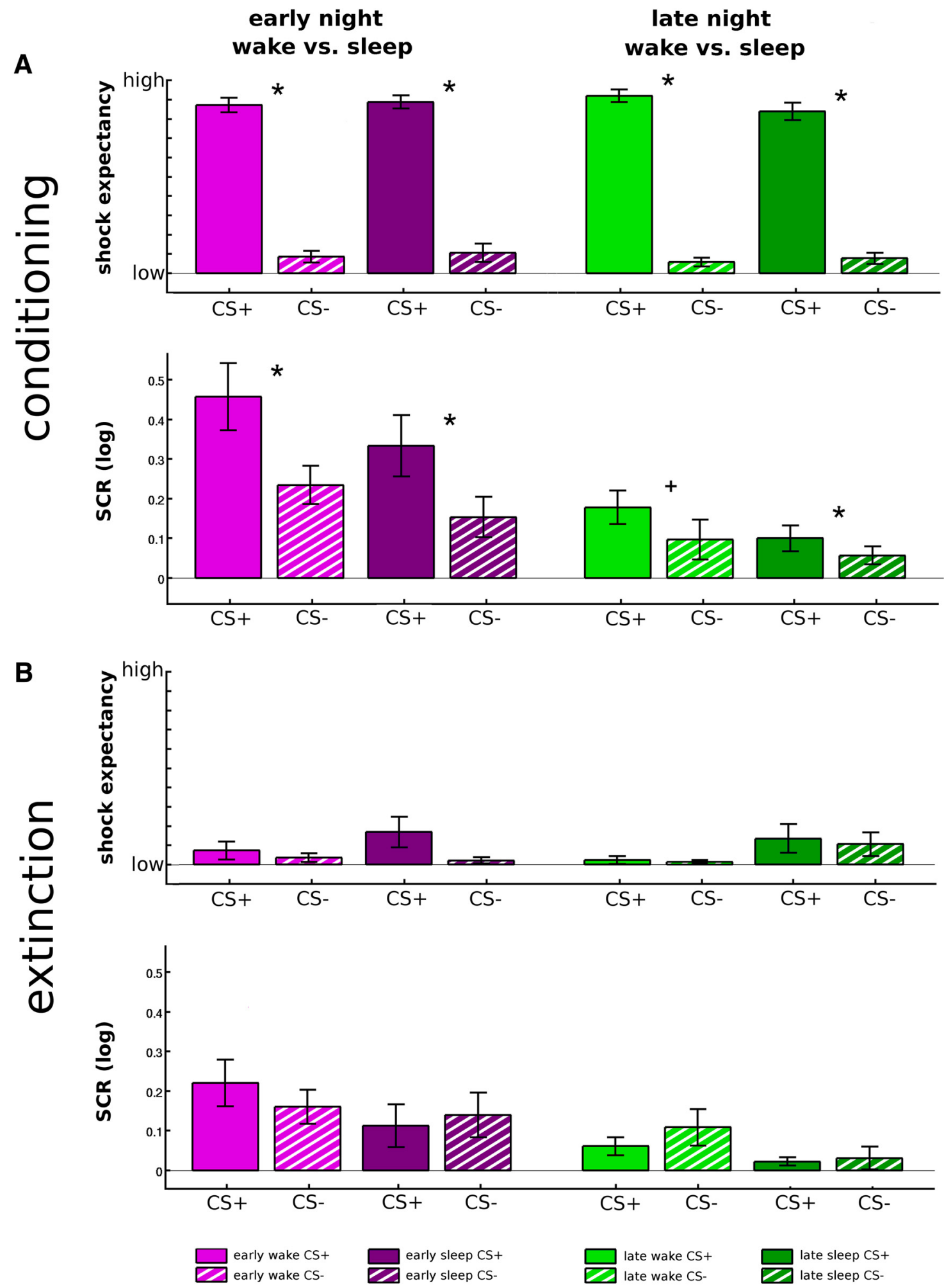

Figure 3. Successful learning in all groups. $\boldsymbol{A}, \boldsymbol{B}$, Subjects learned to discriminate between $C S+$ and $C S-(\boldsymbol{A})$ and ceased to do so after extinction (B). Shock expectancy ratings are in arbitrary units. SCRs describe increases in amplitude (in microsiemens, logarithmized) for the last three trials of each condition. Error bars indicate SEM. Asterisks indicate statistical differences at $p<0.05$. The $p$ value for the difference between $C S+$ and $C S$ - at the end of conditioning in the late wake group (indicated by a plus) is 0.054 .

by larger absolute values and a large (positive) difference between $\mathrm{CS}+\mathrm{E}$ and $\mathrm{CS}-\mathrm{E}$.

Similar to fear recall, extinction recall was not improved by early night sleep. Again, only the late night sleep manipulation led to differences between groups.
In more detail, differentiation in shock expectancy ratings remained similar for both early night groups (Fig. 5, upper left; group difference for corrected CS $+\mathrm{E}>\mathrm{CS}-\mathrm{E}$ : expectancy ratings: $Z=0.08, p=0.94)$ with CS $+\mathrm{N}$ and CS $-\mathrm{N}$ increasing comparably yet slightly (recovery indices, $>0$ ). Also differential 


\section{early night wake vs. sleep}

\section{late night wake vs. sleep}

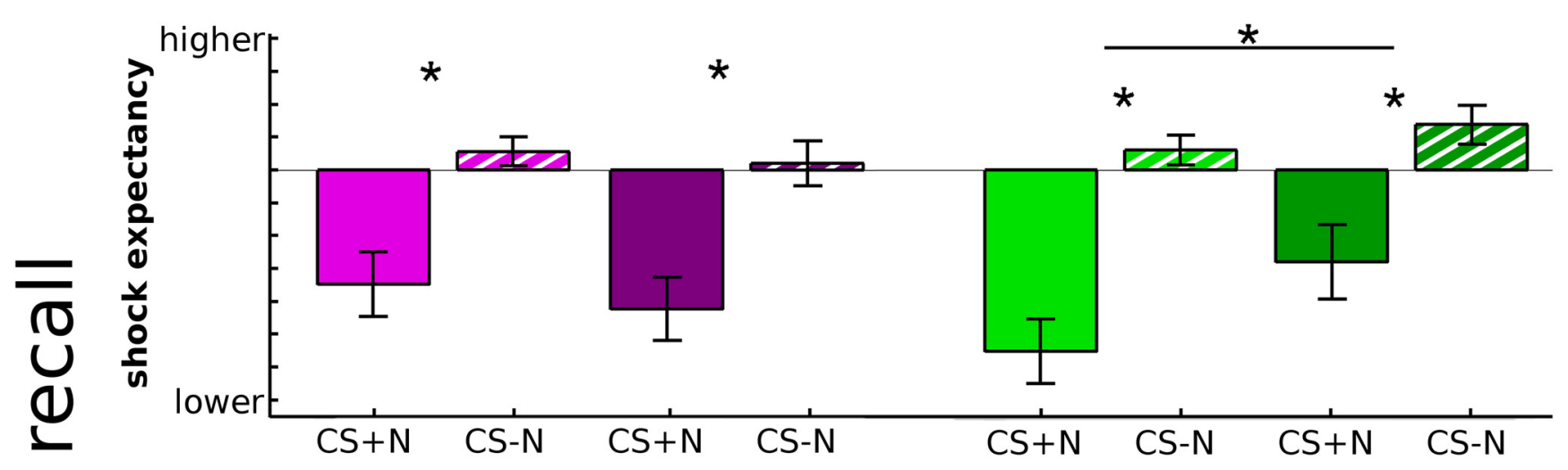

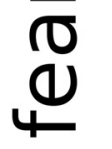

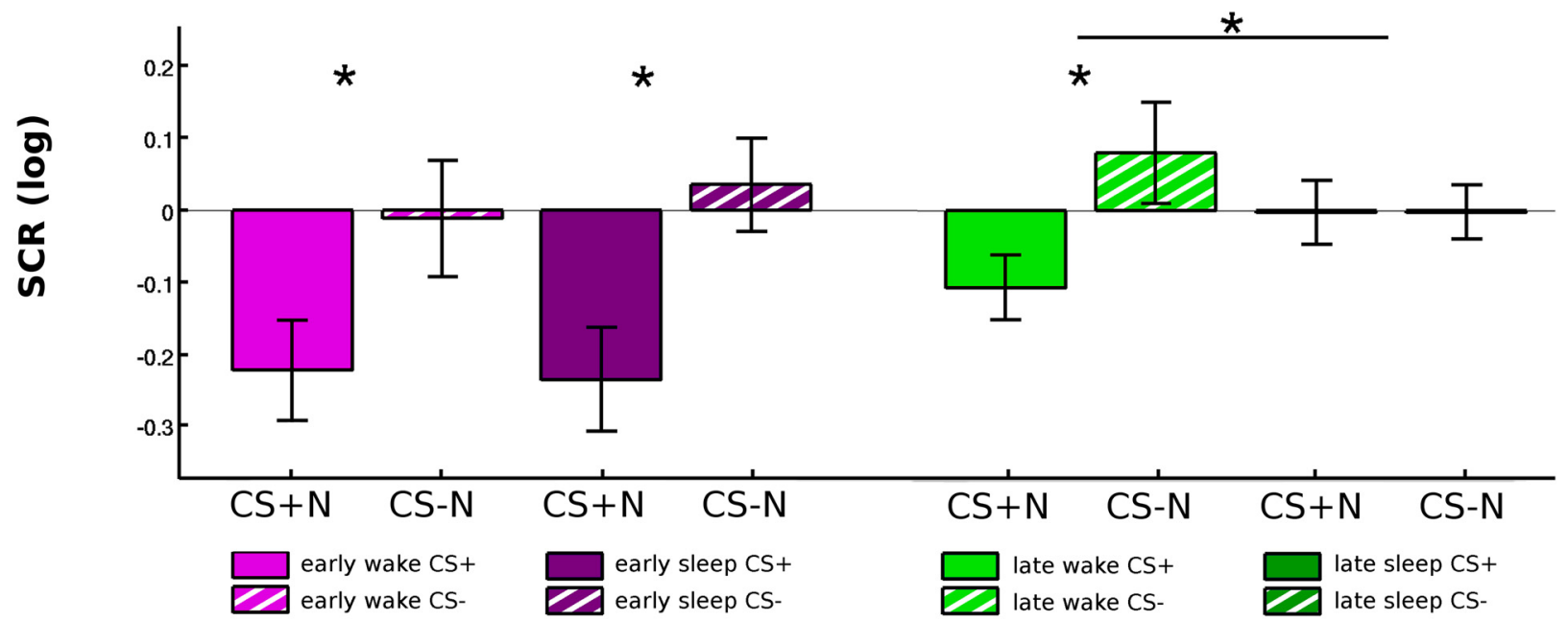

Figure 4. Fear recall after sleep intervention. Early night sleep intervention (left bars in magenta/purple) led to comparable recall performance for dangerous and safety stimuli in the early wake and early sleep group. Thereby, the differentiation between $C S+N$ and $C S-N$ decreased in a similar way and amount (loss of fear toward $C S+N)$. After late night intervention (right bars in green), the late sleep group shows best fear consolidation indicated by the smallest changes of shock expectancy ratings (upper right) and SCR (lower right) between acquisition and recall in CS $+\mathrm{N}>$ CS -N processing. Bars describe recovery indices (i.e., changes from learning to recall) with rising bars describing an increase in fear during memory consolidation while falling bars depict a decrease of fear overnight. Upper panel depicts shock expectancy ratings in arbitrary units; lower panel depicts SCRs, i.e., increases in amplitude (microsiemens, logarithmized). Error bars indicate SEM. Asterisks indicate statistical differences at $p<0.05$.

skin conductance amplitudes $(\mathrm{CS}+\mathrm{E}>\mathrm{CS}-\mathrm{E}$; Fig. 5, bottom left; group difference of $\left.\mathrm{CS}+\mathrm{E}>\mathrm{CS}-\mathrm{E}: T_{(36)}=0.72, p=0.76\right)$ remain similar in both groups, with reaction to all stimuli decreasing slightly.

With this lack of behavioral and neurophysiological evidence for an impact of early night sleep on the consolidation of extinction memory, we waived imaging analysis of extinction recall differences between early wake and early sleep groups.

Comparisons between late wake and late sleep groups, however, showed differences in processing CS +E $>$ CS $-\mathrm{E}$ (Fig. 5, right; Table 2, bottom row). This is driven by larger discrimination between $\mathrm{CS}+\mathrm{E}$ and $\mathrm{CS}-\mathrm{E}$ in the late wake group (SCR: $T_{(30)}=1.74, p=0.046$; expectancy ratings: $\left.Z=1.81, p=0.04\right)$. In more detail, participants in the late wake group express more fear during CS +E presentation compared with CS-E presentation (Fig. 5, left), while participants in the late sleep group maintain their discrimination (i.e., no discrimination) after consolidation.

Altered extinction recall in the late wake group was also reflected in the brain. Figure 6 and Table 3 report the results from the comparison of CS discrimination $(\mathrm{CS}+\mathrm{E}$ vs $\mathrm{CS}-\mathrm{E})$ between late wake and late sleep groups. In agreement with the differential return of fear in behavioral and autonomic data, participants from the late wake group showed stronger activations in a number of areas, including the $\operatorname{vmPFC}\left(x, y, z=3,32,-20 ; Z_{\mathrm{MAX}}=\right.$ 4.03, $p<0.01$, FWE-corrected within ROI) and the amygdala $\left(x, y, z=-8,-27,-14 ; Z_{\mathrm{MAX}}=3.99, p<0.01\right.$, FWE-corrected within ROI) for the differential contrast between CS $+\mathrm{E}>\mathrm{CS}-\mathrm{E}$ compared with the late sleep group.

Parameter estimates for differential activity in the amygdala for the contrast $\mathrm{CS}+\mathrm{E}>\mathrm{CS}-\mathrm{E}$ derived from individual amygdala peaks from all subjects (late wake and late sleep groups) correlated positively with differential skin conductance amplitudes (Fig. $6 C ; r=0.38, p=0.046$, Bonferroni-corrected).

\section{Discussion}

In this study, we targeted discrimination performance during fear and extinction memory recall after a split-night sleep manipulation. Such a design provides the opportunity to determine the relative amount of SWS and REM sleep during consolidation 


\section{early night \\ wake vs. sleep}

\section{late night wake vs. sleep}
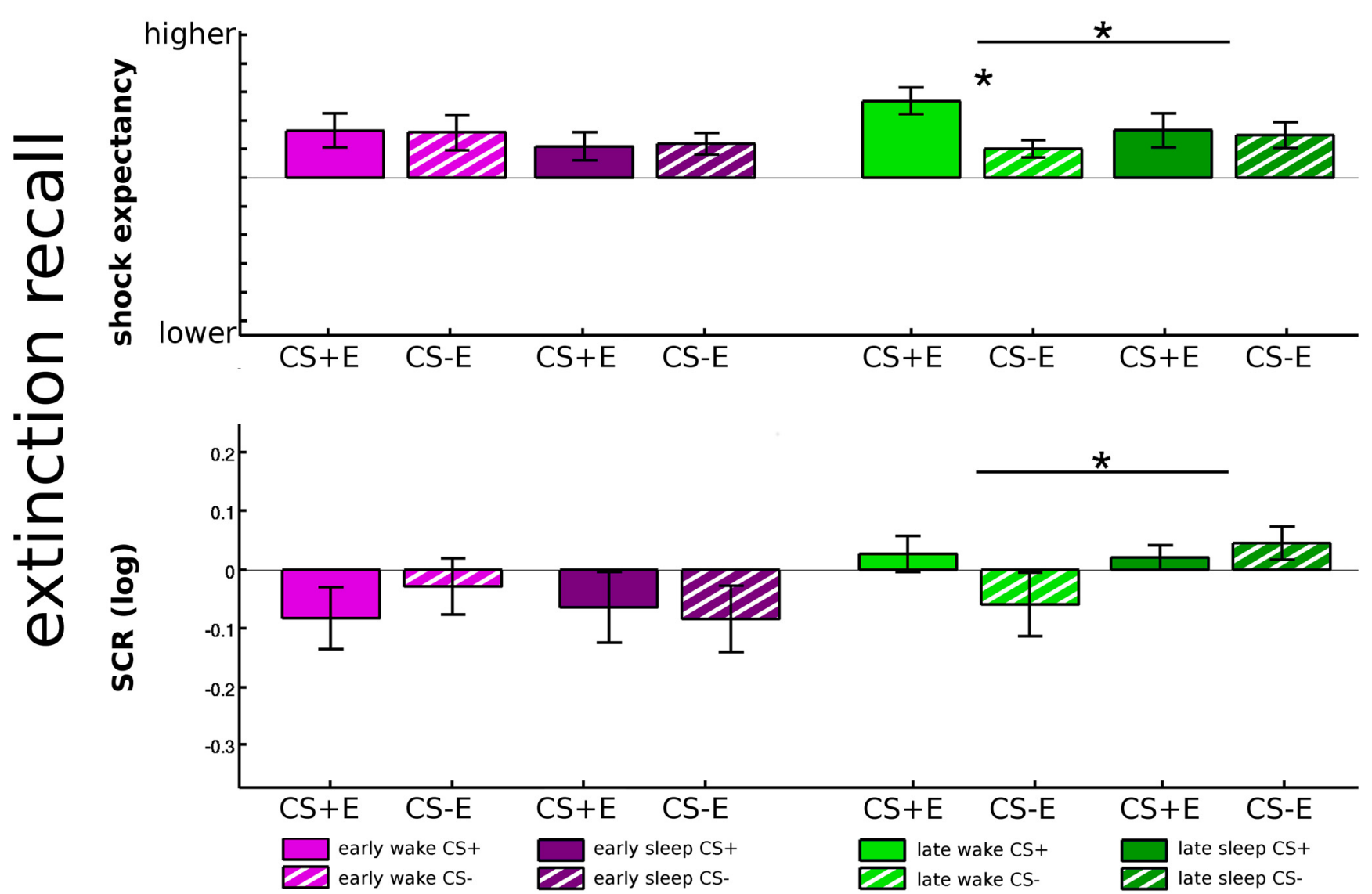

Figure 5. Extinction recall after sleep intervention. Early night sleep intervention (left bars in magenta/purple) led to comparable differentiation recall performance for extinguished from safety stimuli in the early wake and early sleep group. This is illustrated by a comparable deviance of $C S+E$ and $C S$ - Ebars from zero. After late night intervention (right bars in green), the late wake group shows a return of fear [i.e. discrimination between a previously extinguished stimulus and a safe stimulus (CS+E $>C S-E$ )], while the late sleep group maintains differentiation comparable to extinction (both bars rise comparably). Bars describe recovery indices (i.e., changes from learning to recall) with rising bars describing an increase in fear during memory consolidation while falling bars depict a decrease of fear overnight. Error bars indicate SEM. Asterisks indicate statistical differences at $p<0.05$.

regardless of the preceding learning experience. Recall performance after SWS-rich sleep only (early sleep) displayed no change compared with recall after staying awake (early wake). In contrast, recall profited from REM-rich sleep (late sleep) during the second half of the night compared with staying awake during that interval (late wake). Shock expectancy ratings and SCRs demonstrate consolidated fear memory in the late sleep group and impaired extinction memory in the late wake group.

Thus, data in this study negate an independent role of SWS in fear or safety memory consolidation; early groups show comparable behavioral and neurophysiological reactions to $\mathrm{CS}+$ and $\mathrm{CS}-$, respectively. In contrast, the consolidation period seemingly needs to contain a minimum of REM sleep (i.e., more than during the first half of the night) to foster consolidation. Similar to previous results (Menz et al., 2013), REM-rich sleep leads to successful fear recall, as $\mathrm{CS}+\mathrm{N} / \mathrm{CS}-\mathrm{N}$ differentiation is better in the late sleep group. In addition we can show that a lack of REMrich sleep leads to impaired extinction memory consolidation and recall. This becomes apparent in restored differentiation between previously extinguished $\mathrm{CS}+\mathrm{E}$ and $\mathrm{CS}-\mathrm{E}$ and is paralleled by an increase of activation in vmPFC and amygdala in the late wake group.
Ongoing safety learning in vmPFC in the late wake group It has been repeatedly suggested that the vmPFC encodes safety signals. Milad and colleagues report a correlation of vmPFC activation with better retention when they compare extinguished to dangerous stimuli (CS +E $>$ CS $+\mathrm{N}$; Milad et al., 2007). Here, we instead compare the extinguished stimulus $(\mathrm{CS}+\mathrm{E})$ to a safe stimulus (CS-E; Phelps et al., 2004), and find increased vmPFC responses to $\mathrm{CS}-\mathrm{E}$ (i.e., the relatively safer stimulus) only after successful consolidation (late sleep group). We sought to confirm this interpretation with a closer look at the extinction learning data of day $1(n=40)$. During extinction, vmPFC activation to $\mathrm{CS}-\mathrm{E}$ activation is increasing over time $(x, y, z=0,40,-16 ; Z=$ $\left.3.46 ; p_{\mathrm{SVC}}=0.021\right)$. This increased safety signal then drops during the subsequent consolidation of the late wake group while it is further consolidated in the late sleep group, resulting in an increase of $\mathrm{CS}-\mathrm{E}$ activation between extinction and recall.

Strikingly, the larger discrimination between CS+E and $\mathrm{CS}-\mathrm{E}$ in the late wake group seems to be at odds with previous data (Spoormaker et al., 2010) showing an increase of vmPFC activation in subjects who showed REM sleep during napping compared with no-REM subjects. Even parameter estimates show the opposite pattern; that is, vmPFC activation is mainly 
A
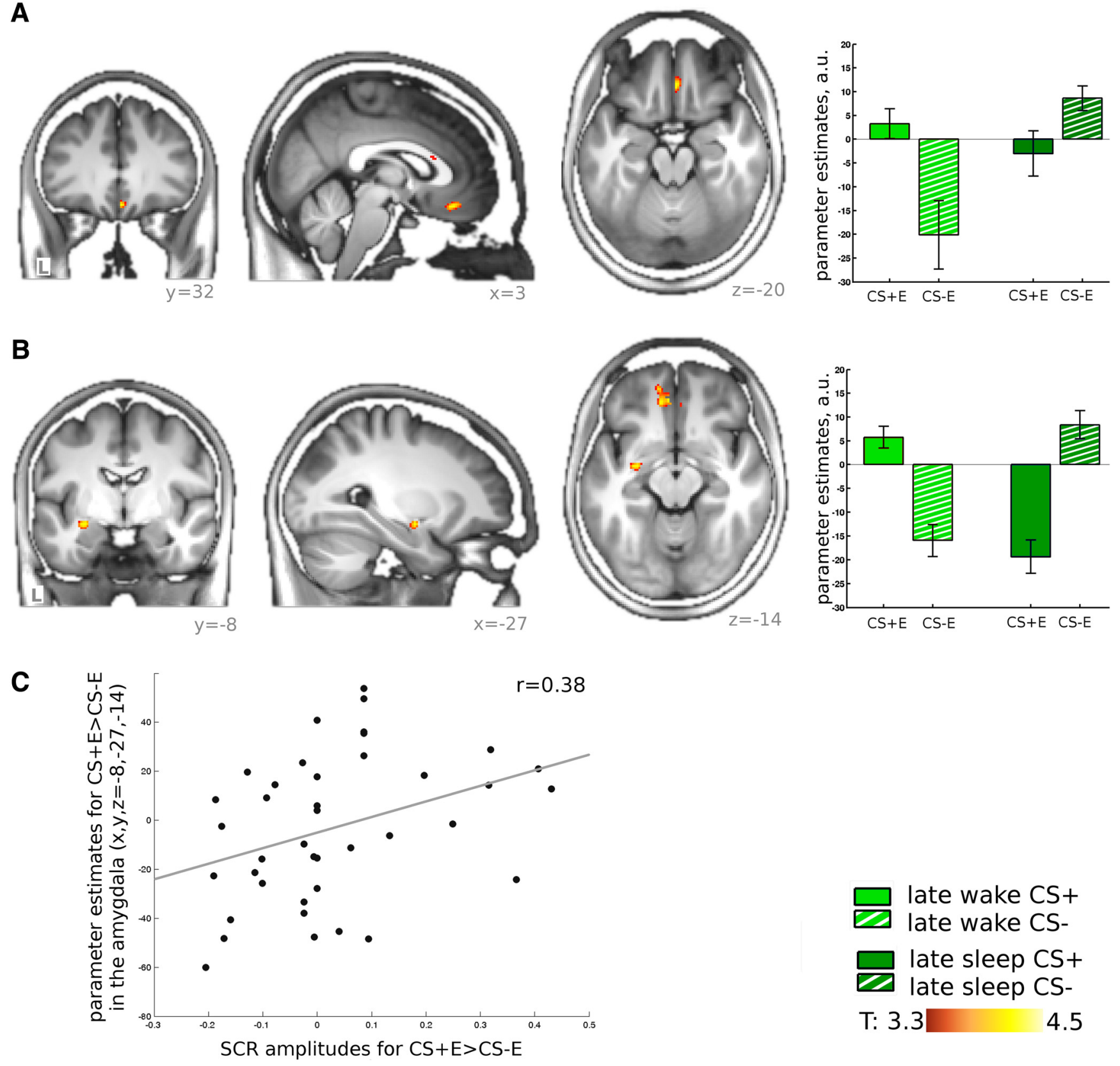

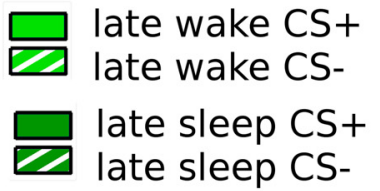

$\mathrm{T}: 3.3 \quad 4.5$

Figure 6. Neuronal correlates of altered extinction recall. The differential activation $C S+E>C S-E$ (in recovery indices, i.e., corrected for acquisition) is stronger in participants of the late wake group compared with the late sleep group (two-sample $t$ test for day-by-condition interactions). $\boldsymbol{A}$, Ongoing safety learning in the vmPFC. $\boldsymbol{B}$, Return of fear in the amygdala (and vmPFC). $\boldsymbol{C}$, the correlation between increase in differential activation (CS+E $>C S-E)$ in amygdala and increase in $\mathrm{SCR}$ amplitudes. Images are thresholded at $p<0.001$, uncorrected (40 contiguous voxels minimum cluster size), and superimposed on the mean $\mathrm{T}_{1}$ image of all participants. Activation of vmPFC $(x, y, z=3,32,-20)$ and amygdala $(x, y, z=-8,-27,-14)$ remain significant $(p<$ 0.01) after FWE correction for multiple comparisons within regions of interest.

driven by increased CS- activation in the no-REM group, while we observe a stronger deactivation in the CS- condition of the late wake group. Possible reasons for these different results include the following: invalid comparisons between napping to nocturnal sleep intervention, invalid comparisons between recovery indices and pure recall, and the use of statistics from first trials only instead of the whole recall session as a basis for conclusions. Finally, another intriguing explanation may be related to the nature of sleep interventions. Using post hoc assignment according to polysomnography data makes inference of causality more difficult and cannot exclude other common denominators of increased REM sleep and better recall performance (Spoor- maker et al., 2010). This is different in split-night paradigms, in which random group assignment explains the amount of REM sleep.

\section{Return of fear in the amygdala}

A functional correlation between vmPFC and amygdala has been reported for extinction (Schiller et al., 2013) and extinction recall (Milad et al., 2007) and may be explained by an inhibitory BOLD response in the amygdala following vmPFC signaling via projections from the vmPFC to principal neurons (Strobel et al., 2015) and inhibitory GABAergic intercalated cells (Milad and Quirk, 2002, 2012; Milad et al., 2007) in the basolateral amygdala. 
Table 3. Return of fear

\begin{tabular}{lllllll}
\hline \multirow{2}{*}{ Site } & & \multicolumn{3}{c}{ Coordinates (MNI) } \\
\cline { 5 - 7 } & Cluster size & $Z_{\text {MAX }}$ & & & $y$ & $z$ \\
\hline Left vmPFC & 190 & 4.0471 & -4 & 39 & -15 \\
& & 3.7893 & -12 & 48 & -14 \\
Left amygdala & 56 & $4.0272^{* *}$ & -27 & -8 & -14 \\
Right vmPFC & 65 & $3.9924^{* *}$ & 3 & 32 & -20 \\
Right cerebral white matter (corpus callosum) & 61 & 3.9102 & 8 & 22 & 18 \\
Right anterior cingulate gyrus & 61 & 3.6232 & 10 & 34 & 6 \\
& & 3.4330 & 8 & 40 & -2 \\
Left paracingulate gyrus & 46 & 3.5662 & -6 & 44 & 0 \\
\hline
\end{tabular}

During recall, participants in the late wake group showed a stronger differential activation between conditioned and extinguished stimuli compared with neutral stimuli ( $C S+E>C S-E$; each corrected for acquisition). Regions were thresholded at $p<0.001$, uncorrected, with 40 voxel minimum cluster size, and determined following anatomical landmarks on the mean $\mathrm{T}_{1}$ image normalized to a DARTEL template.

**Regions were small-volume corrected $\left(p_{\mathrm{FWE}-\mathrm{SvC}}<0.01\right)$ in the a priori defined regions of interest.

Additionally, Milad and colleagues report an absence of differential $(\mathrm{CS}+\mathrm{E}>\mathrm{CS}-\mathrm{E})$ response at the end of extinction while $\mathrm{CS}+\mathrm{E}$ amplitude stays approximately the same height during later recall (Milad et al., 2007). This is the same pattern we observe in the late sleep group. However, the late wake group shows a CS + E response that corresponds approximately to SCR activation at the end of conditioning (compare Figs. 5, 3). This leads to a differentiation between CS $+\mathrm{E}$ and $\mathrm{CS}-\mathrm{E}$ in SCR amplitudes correlating positively with parameter estimates in the amygdala $(r=0.38, p=0.048$, Bonferroni-corrected). That is, differential $(\mathrm{CS}+\mathrm{E}>\mathrm{CS}-\mathrm{E})$ activation in the amygdala is linked to stronger differential SCR amplitudes. We conclude that inhibitory processes relating to increased need of processing of safety signals (as described above) may act in concert with a larger return of fear. Interestingly, temporal dynamics of amygdala activation throughout the whole recall session characterize differential activation as decreasing over time in the same coordinates as the main effect $\left(x, y, z=-27,-8,-14 ; Z=4.18, p_{\mathrm{SVC}}=0.002\right)$, which corresponds to previous reports of conditioning and extinction processes (LaBar et al., 1998; Phelps et al., 2004). Together, vmPFC and amygdala activation in the late wake group suggests that sleep interacts with both fear and safety memory traces generated during conditioning and extinction, respectively, and thereby influences extinction recall in at least two ways.

We can only speculate about why we previously could not report an effect of full night sleep on extinction consolidation (Menz et al., 2013). Paradigm, stimuli, and procedures (e.g., UCS readjustment preceding recall) were identical in both studies. The main difference is the time of learning. Circadian influences and the cognitive ability to learn in the middle of the night possibly constrained learning, while vulnerable extinction memory is more susceptible to spontaneous recovery (Pavlov, 1927; Rescorla, 2004). Additionally, the consolidation periods were generally shorter in this study. These explanations might also hold for fear memory learning and consolidation, thereby explaining why neuronal correlates of better fear recall $(\mathrm{CS}+\mathrm{N}>\mathrm{CS}-\mathrm{N})$ are absent in this study.

\section{A split-night sleep intervention?}

Three major concerns have been raised over split-night interventions.

First, early and late sleep coincide with hormonal changes (e.g., growth hormone and cortisol), rendering a unique attribution of effects to sleep stages nearly impossible (Genzel et al., 2015). Few studies have directly targeted the interaction between cortisol and sleep on emotional memory consolidation (Plihal and Born, 1999; Wilhelm et al., 2011; van Marle et al., 2013;
Bennion et al., 2015) and their results remain inconclusive. We included control groups for early and late night, respectively, to minimize this effect.

Second, a split-night paradigm comes at the cost of an imperfect dichotomization between SWS and REM sleep. This, however, facilitates undisturbed night sleep. Interestingly, REM sleep deprivation or REM sleep suppression (Vertes and Eastman, 2000) might also not be as clear-cut as intended (Born and Gais, 2000) and may induce cognitive and emotional disturbances (Gais et al., 2000) as well as stress-related elevations in cortisol levels leading to effects similar to cortisol release during REM sleep itself (van Marle et al., 2013; Genzel et al., 2015). An elegant solution to investigate the connection between sleep stages and consolidation is offered by correlational analyses between individual sleep architecture (e.g., minutes spent in SWS or number of sleep spindles) and recall performance (Durrant et al., 2011; Spoormaker et al., 2012; Tamminen et al., 2013; Cairney et al., 2015). However, the general architecture of sleep is known to be generally altered in post-training nights (Maquet, 2001; Smith et al., 2004). Hence an increase of REM sleep can also be attributed to learning.

Finally, staying awake is an imperfect baseline condition. Information processing during wakefulness may interfere retroactively with acquisition (Robertson, 2012). In rodents, however, it was shown that post-training stimulation did not alter memory performance in a contextual fear-conditioning task per se (Hagewoud et al., 2010). Next, stress and glucocorticoid release during sleep deprivation may decrease memory performance. However, memory impairments are still evident in animals that underwent adrenalectomy (Tiba et al., 2008). This suggests that neither elevated cortisol levels after sleep deprivation nor retroactive interference can fully explain differences between sleep and wake groups in full-night or split-night paradigms (Havekes et al., 2015). Of note, the control group alternative (i.e., a morningevening/evening-morning paradigm) may be confounded by circadian effects, which has been discussed previously (Menz et al., 2013) and was nicely tested by Pace-Schott et al. (2013), who report stronger extinction learning and recall in the morning compared with the evening.

In summary, we show that REM sleep, but not SWS, following extinction is important for successful recall of safety stimuli and reduces return of fear after successful extinction. Furthermore, we attribute a causal role of REM sleep to successful consolidation. This is vested with the random assignment of participants to groups in a split-night design that circumvents systematic alterations of sleep architecture caused by learning or personality. Thereby, we add an importance piece of the puzzle in augmenting our knowledge on how sleep following extinction (or exposure therapy in clinical terms) may contribute to successful extinction memory consolidation.

\section{Notes}

Supplemental material for this article is available at http://neurovault. org/collections/IKOZGDPH/. NeuroVault Collection of 2nd-level stats and vmPFC ALE map. This material has not been peer reviewed.

\section{References}

Abe M, Schambra H, Wassermann EM, Luckenbaugh D, Schweighofer N, Cohen LG (2011) Reward improves long-term retention of a motor memory through induction of offline memory gains. Curr Biol 21: 557-562. CrossRef Medline

Ai SZ, Chen J, Liu JF, He J, Xue YX, Bao YP, Han F, Tang XD, Lu L, Shi J (2015) Exposure to extinction-associated contextual tone during slow- 
wave sleep and wakefulness differentially modulates fear expression. Neurobiol Learn Mem 123:159-167. CrossRef Medline

Ambrosini MV, Langella M, Gironi Carnevale UA, Giuditta A (1992) The sequential hypothesis of sleep function. III. The structure of postacquisition sleep in learning and nonlearning rats. Physiol Behav 51:217-226. CrossRef Medline

Bennion KA, Mickley Steinmetz KR, Kensinger EA, Payne JD (2015) Sleep and cortisol interact to support memory consolidation. Cereb Cortex 25:646-657. CrossRef Medline

Born J, Gais S (2000) REM sleep deprivation: the wrong paradigm leading to wrong conclusions. Behav Brain Sci 23:912-913. CrossRef

Boucsein W, Fowles DC, Grimnes S, Ben-Shakhar G, Roth WT, Dawson ME, Filion DL (2012) Publication recommendations for electrodermal measurements. Psychophysiology 49:1017-1034. CrossRef Medline

Bouton ME (2004) Context and behavioral processes in extinction. Learn Mem 11:485-494. Medline

Buysse DJ, Reynolds CF 3rd, Monk TH, Berman SR, Kupfer DJ (1989) The Pittsburgh Sleep Quality Index: a new instrument for psychiatric practice and research. Psychiatry Res 28:193-213. CrossRef Medline

Cairney SA, Durrant SJ, Power R, Lewis PA (2015) Complementary roles of slow-wave sleep and rapid eye movement sleep in emotional memory consolidation. Cereb Cortex 25:1565-1575. CrossRef Medline

Diekelmann S, Born J (2010) The memory function of sleep. Nat Rev Neurosci 11:114-126. CrossRef Medline

Durrant SJ, Taylor C, Cairney S, Lewis PA (2011) Sleep-dependent consolidation of statistical learning. Neuropsychologia 49:1322-1331. CrossRef Medline

Eickhoff SB, Laird AR, Grefkes C, Wang LE, Zilles K, Fox PT (2009) Coordinate-based activation likelihood estimation meta-analysis of neuroimaging data: a random-effects approach based on empirical estimates of spatial uncertainty. Hum Brain Mapp 30:2907-2926. CrossRef Medline

Eickhoff SB, Bzdok D, Laird AR, Kurth F, Fox PT (2012) Activation likelihood estimation meta-analysis revisited. Neuroimage 59:2349-2361. CrossRef Medline

Feng P, Feng T, Chen Z, Lei X (2014) Memory consolidation of fear conditioning: bi-stable amygdala connectivity with dorsal anterior cingulate and medial prefrontal cortex. Soc Cogn Affect Neurosci 9:1730-1737. CrossRef Medline

Fenn KM, Nusbaum HC, Margoliash D (2003) Consolidation during sleep of perceptual learning of spoken language. Nature 425:614-616. CrossRef Medline

Fowler MJ, Sullivan MJ, Ekstrand BR (1973) Sleep and memory. Science 179:302-304. CrossRef Medline

Gais S, Plihal W, Wagner U, Born J (2000) Early sleep triggers memory for early visual discrimination skills. Nat Neurosci 3:1335-1339. CrossRef Medline

Garfinkel SN, Abelson JL, King AP, Sripada RK, Wang X, Gaines LM, Liberzon I (2014) Impaired contextual modulation of memories in PTSD: an fMRI and psychophysiological study of extinction retention and fear renewal. J Neurosci 34:13435-13443. CrossRef Medline

Genzel L, Spoormaker VI, Konrad BN, Dresler M (2015) The role of rapid eye movement sleep for amygdala-related memory processing. Neurobiol Learn Mem 122:110-121. CrossRef Medline

Goldstein AN, Walker MP (2014) The role of sleep in emotional brain function. Annu Rev Clin Psychol 10:679-708. CrossRef Medline

Haaker J, Golkar A, Hermans D, Lonsdorf TB (2014) A review on human reinstatement studies: an overview and methodological challenges. Learn Mem 21:424-440. CrossRef Medline

Hagewoud R, Whitcomb SN, Heeringa AN, Havekes R, Koolhaas JM, Meerlo P (2010) A time for learning and a time for sleep: the effect of sleep deprivation on contextual fear conditioning at different times of the day. Sleep 33:1315-1322. Medline

Hauner KK, Howard JD, Zelano C, Gottfried JA (2013) Stimulus-specific enhancement of fear extinction during slow-wave sleep. Nat Neurosci 16:1553-1555. CrossRef Medline

Havekes R, Meerlo P, Abel T (2015) Animal studies on the role of sleep in memory: from behavioral performance to molecular mechanisms. Curr Top Behav Neurosci 25:183-206. CrossRef Medline

Hermann A, Keck T, Stark R (2014) Dispositional cognitive reappraisal modulates the neural correlates of fear acquisition and extinction. Neurobiol Learn Mem 113:115-124. CrossRef Medline

Iber C (2007) The AASM manual for the scoring of sleep and associated events: rules, terminology and technical specifications. Westchester, IL: American Academy of Sleep Medicine.

Johns MW (1991) A new method for measuring daytime sleepiness: the Epworth sleepiness scale. Sleep 14:540-545. Medline

Jokeit H, Ebner A, Holthausen H, Markowitsch HJ, Moch A, Pannek H, Schulz R, Tuxhorn I (1997) Individual prediction of change in delayed recall of prose passages after left-sided anterior temporal lobectomy. Neurology 49:481-487. CrossRef Medline

Jokeit H, Daamen M, Zang H, Janszky J, Ebner A (2001) Seizures accelerate forgetting in patients with left-sided temporal lobe epilepsy. Neurology 57:125-126. CrossRef Medline

Kalisch R, Korenfeld E, Stephan KE, Weiskopf N, Seymour B, Dolan RJ (2006) Context-dependent human extinction memory is mediated by a ventromedial prefrontal and hippocampal network. J Neurosci 26: 9503-9511. CrossRef Medline

LaBar KS, Gatenby JC, Gore JC, LeDoux JE, Phelps EA (1998) Human amygdala activation during conditioned fear acquisition and extinction: a mixed-trial fMRI study. Neuron 20:937-945. CrossRef Medline

Leeson VC, Robbins TW, Franklin C, Harrison M, Harrison I, Ron MA, Barnes TR, Joyce EM (2009) Dissociation of long-term verbal memory and fronto-executive impairment in first-episode psychosis. Psychol Med 39:1799-1808. CrossRef Medline

Lonsdorf TB, Haaker J, Kalisch R (2014) Long-term expression of human contextual fear and extinction memories involves amygdala, hippocampus and ventromedial prefrontal cortex: a reinstatement study in two independent samples. Soc Cogn Affect Neurosci 9:1973-1983. CrossRef Medline

Maquet P (2001) The role of sleep in learning and memory. Science 294: 1048-1052. CrossRef Medline

Marschner A, Kalisch R, Vervliet B, Vansteenwegen D, Büchel C (2008) Dissociable roles for the hippocampus and the amygdala in human cued versus context fear conditioning. J Neurosci 28:9030-9036. CrossRef Medline

Marshall L, Helgadóttir H, Mölle M, Born J (2006) Boosting slow oscillations during sleep potentiates memory. Nature 444:610-613. CrossRef Medline

Menz MM, Rihm JS, Salari N, Born J, Kalisch R, Pape HC, Marshall L, Büchel C (2013) The role of sleep and sleep deprivation in consolidating fear memories. Neuroimage 75:87-96. CrossRef Medline

Milad MR, Quirk GJ (2002) Neurons in medial prefrontal cortex signal memory for fear extinction. Nature 420:70-74. CrossRef Medline

Milad MR, Quirk GJ (2012) Fear extinction as a model for translational neuroscience: ten years of progress. Annu Rev Psychol 63:129-151. CrossRef Medline

Milad MR, Wright CI, Orr SP, Pitman RK, Quirk GJ, Rauch SL (2007) Recall of fear extinction in humans activates the ventromedial prefrontal cortex and hippocampus in concert. Biol Psychiatry 62:446-454. CrossRef Medline

Milad MR, Pitman RK, Ellis CB, Gold AL, Shin LM, Lasko NB, Zeidan MA, Handwerger K, Orr SP, Rauch SL (2009) Neurobiological basis of failure to recall extinction memory in posttraumatic stress Disorder. Biol Psychiatry 66:1075-1082. CrossRef Medline

Myers KM, Davis M (2007) Mechanisms of fear extinction. Mol Psychiatry 12:120-150. Medline

Pace-Schott EF, Spencer RM, Vijayakumar S, Ahmed NA, Verga PW, Orr SP, Pitman RK, Milad MR (2013) Extinction of conditioned fear is better learned and recalled in the morning than in the evening. J Psychiatr Res 47:1776-1784. CrossRef Medline

Pace-Schott EF, Germain A, Milad MR (2015) Effects of sleep on memory for conditioned fear and fear extinction. Psychol Bull 141:835-857. CrossRef Medline

Pavlov IP (1927) Conditioned reflexes. London: Oxford UP

Pejic T, Hermann A, Vaitl D, Stark R (2013) Social anxiety modulates amygdala activation during social conditioning. Soc Cogn Affect Neurosci 8:267-276. CrossRef Medline

Phelps EA, Delgado MR, Nearing KI, LeDoux JE (2004) Extinction learning in humans: role of the amygdala and vmPFC. Neuron 43:897-905. CrossRef Medline

Plihal W, Born J (1997) Effects of early and late nocturnal sleep on declarative and procedural memory. J Cogn Neurosci 9:534-547. CrossRef Medline 
Plihal W, Born J (1999) Effects of early and late nocturnal sleep on priming and spatial memory. Psychophysiology 36:571-582. CrossRef Medline

Rechtschaffen A, Kales A (1968) A manual of standardized terminology, techniques and scoring system for sleep stages of human subjects. Bethesda, MD: U.S. Department of Health.

Rescorla RA (2004) Spontaneous recovery. Learn Mem 11:501-509. CrossRef Medline

Robertson EM (2012) New insights in human memory interference and consolidation. Curr Biol 22:R66-R71. CrossRef Medline

Rougemont-Bücking A, Linnman C, Zeffiro TA, Zeidan MA, Lebron-Milad K, Rodriguez-Romaguera J, Rauch SL, Pitman RK, Milad MR (2011) Altered processing of contextual information during fear extinction in PTSD: an fMRI study. CNS Neurosci Ther 17:227-236. CrossRef Medline

Sanford LD, Tang X, Ross RJ, Morrison AR (2003) Influence of shock training and explicit fear-conditioned cues on sleep architecture in mice: strain comparison. Behav Genet 33:43-58. CrossRef Medline

Schiller D, Kanen JW, LeDoux JE, Monfils, MH, Phelps EA (2013) Extinction during reconsolidation of threat memory diminishes prefrontal cortex involvement. Proc Natl Acad Sci U S A 110:20040-20045. CrossRef Medline

Seidman LJ, Stone WS, Jones R, Harrison RH, Mirsky AF (1998) Comparative effects of schizophrenia and temporal lobe epilepsy on memory. J Int Neuropsychol Soc 4:342-352. Medline

Smith CT, Nixon MR, Nader RS (2004) Posttraining increases in REM sleep intensity implicate REM sleep in memory processing and provide a biological marker of learning potential. Learn Mem 11:714-719. CrossRef Medline

Smith ML, Milner B (1981) The role of the right hippocampus in the recall of spatial location. Neuropsychologia 19:781-793. CrossRef Medline

Spoormaker VI, Sturm A, Andrade KC, Schröter MS, Goya-Maldonado R, Holsboer F, Wetter TC, Sämann PG, Czisch M (2010) The neural correlates and temporal sequence of the relationship between shock exposure, disturbed sleep and impaired consolidation of fear extinction. J Psychiatr Res 44:1121-1128. CrossRef Medline
Spoormaker VI, Schröter MS, Andrade KC, Dresler M, Kiem SA, Goya-Maldonado R, Wetter TC, Holsboer F, Sämann PG, Czisch M (2012) Effects of rapid eye movement sleep deprivation on fear extinction recall and prediction error signaling. Hum Brain Mapp 33:2362-2376. CrossRef Medline

Strobel C, Marek R, Gooch HM, Sullivan RKP, Sah P (2015) Prefrontal and auditory input to intercalated neurons of the amygdala. Cell Rep pii: S2211-1247(15)00136-9. CrossRef Medline

Suchecki D, Tiba PA, Machado RB (2012) REM sleep rebound as an adaptive response to stressful situations. Front Neurol 3:41. CrossRef Medline

Tamminen J, Lambon Ralph MA, Lewis PA (2013) The role of sleep spindles and slow-wave activity in integrating new information in semantic memory. J Neurosci 33:15376-15381. CrossRef Medline

Tiba PA, Oliveira MG, Rossi VC, Tufik S, Suchecki D (2008) Glucocorticoids are not responsible for paradoxical sleep deprivation-induced memory impairments. Sleep 31:505-515. Medline

Turkeltaub PE, Eden GF, Jones KM, Zeffiro TA (2002) Meta-analysis of the functional neuroanatomy of single-word reading: method and validation. Neuroimage 16:765-780. CrossRef Medline

van Marle HJ, Hermans EJ, Qin S, Overeem S, Fernández G (2013) The effect of exogenous cortisol during sleep on the behavioral and neural correlates of emotional memory consolidation in humans. Psychoneuroendocrinology 38:1639-1649. CrossRef Medline

Vertes RP, Eastman KE (2000) The case against memory consolidation in REM sleep. Behav Brain Sci 23:867-876. CrossRef Medline

Vervliet B, Craske MG, Hermans D (2013) Fear extinction and relapse: state of the art. Annu Rev Clin Psychol 9:215-248. CrossRef Medline

Walker MP, Stickgold R (2006) Sleep, memory, and plasticity. Annu Rev Psychol 57:139-166. CrossRef Medline

Wilhelm I, Wagner U, Born J (2011) Opposite effects of cortisol on consolidation of temporal sequence memory during waking and sleep. J Cogn Neurosci 23:3703-3712. CrossRef Medline

Yaroush R, Sullivan MJ, Ekstrand BR (1971) Effect of sleep on memory: II. Differential effect of the first and second half of the night. J Exp Psychol 88:361-366. CrossRef Medline 